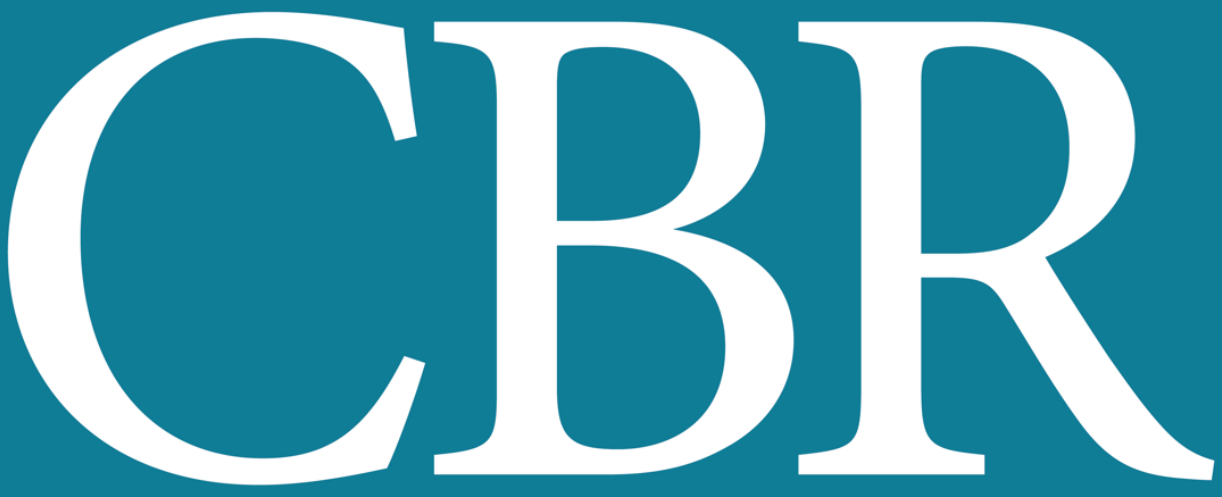

INTERNATIONAL JOURNAL OF CANCER AND BIOMEDICAL RESEARCH

https://jcbr.journals.ekb.eg

Editor-in-chief

Prof. Mohamed Labib Salem, PhD

Autovaccination with attenuated inflammatory cells ameliorates imiquimod induced psoriasisHke skin inflammation in mice

Samar Salman, Mohamed L. Salem, Amany Abdel-Latif and Yasmina A. El Attar 


\section{Welcome letter from Editor-in-Chief}

Welcome to the Int J Cancer and Biomedical Research (IJCBR)!

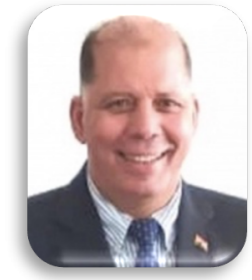

It is with great pleasure that I write this editorial to welcome you to the IJCBR. This journal provides a platform for publication of original and reviews research articles, short communications, letter to editor, thesis abstract, conference report, and case studies. These types of publication are directed at the interface of the fields of cancer and biomedical research.

The IJCBR relies on a distinguished expert of the Advisory and Editorial Board Members from the top international league covering in depth the related topics. They timely review all manuscripts and maintain highest standards of quality and scientific methodology and ethical concepts. Meanwhile, we take all possible means to keep the time of the publication process as short as possible.

I take this chance to welcome your contributions to the IJCBR and have every expectation that it will soon become one of the most respected journals in both the fields of cancer and biomedical research.

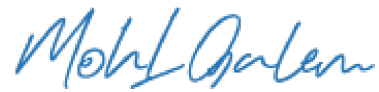

Mohamed L. Salem,

Editor in Chief 


\title{
Autovaccination with attenuated inflammatory cells ameliorates imiquimod induced psoriasis-like skin inflammation in mice
}

\author{
Samar Salman¹, Mohamed L. Salem², Amany Abdel-Latif ${ }^{3}$ and Yasmina A. El Attar ${ }^{3}$ \\ ${ }^{1}$ Dermatology Department, Faculty of Medicine, Tanta University, Tanta, Egypt \\ 2Zoology Department, Faculty of Science, and Center of Excellence in Cancer Research, Tanta University Teaching Hospital, \\ Tanta University, Tanta, Egypt \\ ${ }^{3}$ Department of Dermatology and Venereology, Tanta University Hospital, Tanta University, Tanta, Egypt
}

\section{III}

ABSTRACT

Background: Psoriasis is a complex immune-mediated inflammatory disease that occurs in a genetically susceptible individual. Aim: In this study, we aimed to test whether the use of autovaccine containing different attenuated inflammatory cells could ameliorate the inflammatory process in a psoriasis-like skin inflammation model. Materials and Methods: After six days of IMQ application, the psoriasis-like skin inflammation was developed. After six days of IMQ application, the psoriasislike skin inflammation was developed. Results: After seven days of treatment (14 days of IMQ), the mice treated with the autovaccine showed the most significant improvement as reflected by PASI score. Treatment with autovaccine also induced the best significant decrease of the epidermal thickness as compared to the other treatments $(P<0.01)$, where the complete disappearance of prurigo nodularis like skin lesions was observed. Conclusion: Taken our results together, it can be suggested that autovaccination by the attenuated inflammatory cells found in skin lesions of psoriasis-like inflammation can be a therapeutic modality for such kind of inflammatory reaction.

Editor-in-Chief: Prof. M.L. Salem, Ph.D. - Article DOI: 10.21608/JCBR.2020.34976.1050
ARTICLE INFO

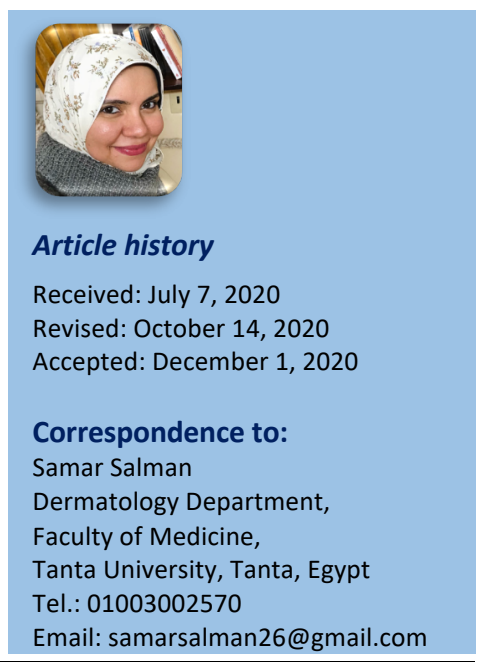

\section{INTRODUCTION}

Psoriasis is a complex immune-mediated inflammatory disease that occurs in genetically susceptible individuals (Ogawa et al. 2018). The role of the immune system in psoriasis has a significant impact on treatment development (Lowes et al., 2014). The use of attenuated autologous $T$ cell vaccination has been evolved as a therapeutic modality for inflammatory and autoimmunity diseases (Huang et al. 2016; Huang et al., 2014). In this study, we aimed to test whether the use of autovaccine containing different attenuated inflammatory cells could ameliorate the inflammatory process in a psoriasis-like skin inflammation model.

The psoriasis-like model was induced as previously described (van der Fits et al. 2009). The dorsal skin of the mice $(n=20)$ was shaved and 5\% Imiquimod "IMQ" cream (Aldara, 3M Pharmaceuticals) was topically applied at a dose of $62.50 \mathrm{mg}$ for six consequent days. The animal studies were carried out according to the institutional ethical committee guidelines. Animal investigations were carried out to a high ethical standard. All experimental procedures were approved by Research ethics guidelines by Tanta University.

\section{RESULTS}

After six days of IMQ application, the psoriasislike skin inflammation was developed. One mouse was sacrificed and a skin biopsy ( $2 \times 2.5$ $\mathrm{cm}$ ) from the skin lesions was harvested under sterile conditions (Johnson 2012). The autovaccine was prepared by homogenizing the harvested biopsy by grinding them with a pestle and a mortar using liquid nitrogen. Under this setting, these attenuated inflammatory cells in the skin biopsy are considered as the autovaccine. On day 7 of IMQ treatment, the inflamed mice ( $n=6 /$ group) were given an intralesional injection of $1 \mathrm{ml} / \mathrm{mouse}$ Phosphate-buffered saline, $1 \mathrm{ml} /$ mouse 
autovaccine (divided into multiple skin lesions), or treated with topical application of betamethasone cream ( $1 \mathrm{mg} / \mathrm{mouse} /$ day) (Mori et al. 2016). Clinical improvement was determined by the objective Psoriasis Area and Severity Index "PASI" score (the index included erythema, scales, and thickening). Each index was scored independently on a scale from 0 to 4, where 0: none, 1: slight, 2: moderate, 3: marked, 4: maximum. The mean difference of the epidermal thickness among the different groups was recorded. After 6 days of IMQ application and before treatment, we noticed prurigo nodularis like skin lesions that appeared in all groups as compared to naïve mice (Figure 1). After seven days of treatment (14 days of IMQ), the mice treated with the autovaccine showed the most significant improvement as reflected by PASI score as compared to treatment with PBS or the conventional drug (Figure 2). Treatment with autovaccine also induced the best significant decrease of the epidermal thickness as compared to the other treatments $(p<0.01)$, where the complete disappearance of prurigo nodularis like skin lesions was observed. Treatment of inflamed mice with autovaccination ameliorated most of the IMQ-induced histopathological changes, including acanthosis, papillomatosis, parakeratosis, and infiltration of inflammatory cells in the dermis (Figure 2).

Taken our results together, it can be suggested that autovaccination by the attenuated inflammatory cells found in skin lesions of psoriasis-like inflammation can be a therapeutic modality for such kind of inflammatory reaction.

Over the past decades, the effect of autologous $T$ cell vaccine has been justified in several animal models of autoimmune diseases including experimental autoimmune encephalomyelitis murine autoimmune diabetes in nonobese diabetic mice, and collagen-induced arthritis (Kroger et al. 2018; Borghans et al. 1998; X. Huang, Wu, and Lu 2014). The rationale behind the efficacy of this vaccine has been accepted based on the observation that immunization with attenuated autoreactive T cells is capable of inducing T celldependent inhibition of autoimmune responses. The mechanism behind the efficacy of $T$ cell vaccine has been subjected to be mediated by eliminating the autoreactive $T$ cells (X. Huang, Wu, and Lu 2014). Indeed, our histopathological results from the autovaccinated mice showed multiple rich inflammatory cells including $T$ cells, dendritic cells, and neutrophils (Figure 2). Our possible mechanisms of action for the autovaccine are through reinjection of attenuated $\mathrm{T}$ cell and/or the transfer of some inhibitory cytokines and inflammatory cells. Our proposed method for autovaccination could be generalized for also other inflammatory and autoimmunity dermatological conditions as vitiligo, pemphigus, atopic dermatitis and other similar conditions. It is considered as a simple and cheap approach that can achieve satisfactory results.
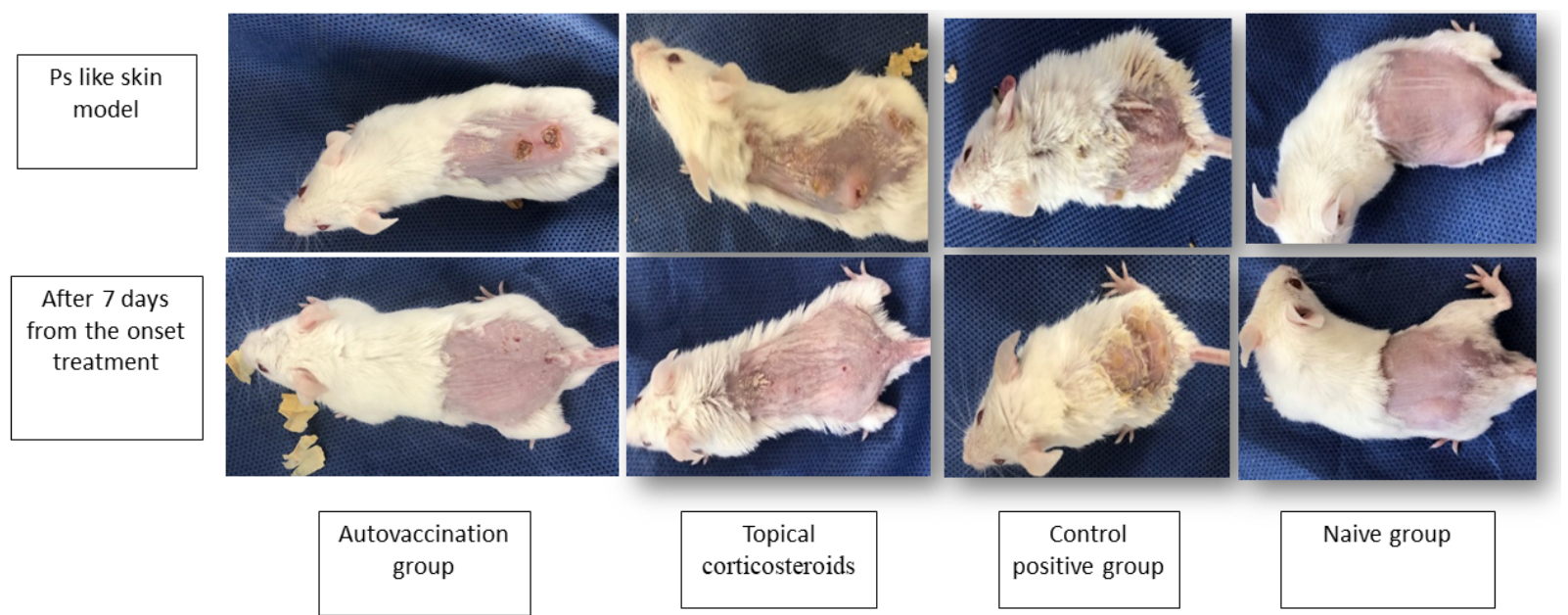

Autovaccination group
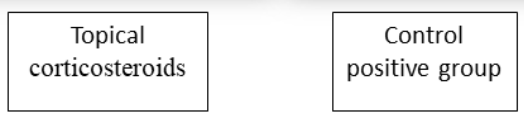

Figure 1. The response after seven days in each group 


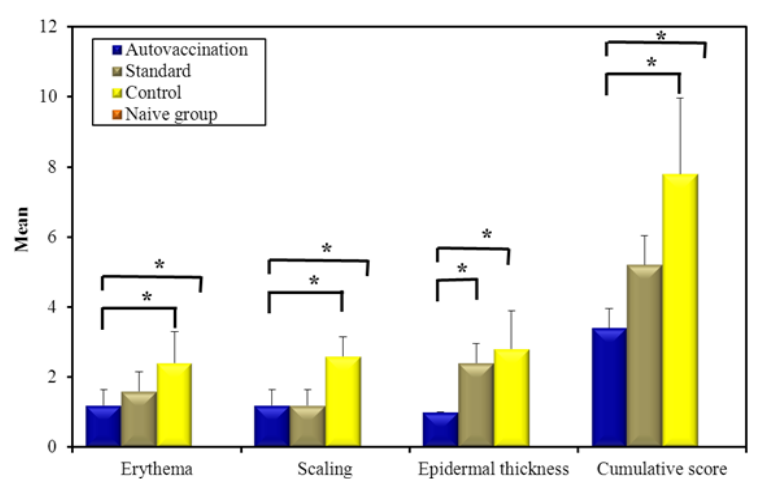

Figure 2. Comparison between different studied groups according to different parameters

\section{CONCLUSION}

Our results in psoriasis-like skin inflammation may uncover some possible mechanisms of the action of auto-transplantation that has been used in different autoimmune diseases. For example, in vitiligo, melanocyte transplantation is a well-established modality where the epidermis or a full skin thickness is transplanted in the vitiliginous areas (Zokaei et al. 2019). According to our pilot study, we suggest that the transfer of inhibitory anti-inflammatory cells from the transplant could attenuate the inflammatory response and improve vitiligo. Further experimental and clinical studies are needed to assess our novel method of attaining rich inflammatory infiltrate and its possible use in an attenuated form as an autovaccine for the treatment of inflammatory and autoimmunity syndromes.

\section{CONFLICT OF INTEREST}

Authors declare that they have no conflicts of interest.

\section{FUDING}

There is no financial support for this study.

\section{REFERENCES}

Borghans, José A M, Rob J De Boer, Eli Sercarz, and Vipin Kumar. 1998. "T Cell Vaccination in Experimental Autoimmune Encephalomyelitis: A Mathematical Model." The Journal of Immunology 161 (3): $1087 \quad$ LP-1093. http://www.jimmunol.org/content/161/3/108 7.abstract.
Fits, L. van der, S. Mourits, J. S. A. Voerman, M. Kant, L. Boon, J. D. Laman, F. Cornelissen, et al. 2009. "Imiquimod-Induced Psoriasis-Like Skin Inflammation in Mice Is Mediated via the IL23/IL-17 Axis." The Journal of Immunology 182 (9): 5836-45. https://doi.org/10.4049/jimmunol.0802999.

Huang, Liuye, Yuan Yang, Yu Kuang, Dapeng Wei, Wanyi Li, Qin Yin, Juan Pang, and Zhongwei Zhang. 2016. "The Impact of T Cell Vaccination in Alleviating and Regulating Systemic Lupus Erythematosus Manifestation" 2016.

Huang, Xin, Haijing Wu, and Qianjin Lu. 2014. "The Mechanisms and Applications of $\mathrm{T}$ Cell Vaccination for Autoimmune Diseases: A Comprehensive Review," 219-33. https://doi.org/10.1007/s12016-014-8439-6.

Johnson, Mary. 2012. "Laboratory Mice and Rats." Materials and Methods 2 (October). https://doi.org/10.13070/mm.en.2.113.

Kroger, Charles J, Matthew Clark, Qi Ke, and Roland M Tisch. 2018. "Therapies to Suppress $\beta$ Cell Autoimmunity in Type 1 Diabetes ." Frontiers in Immunology

https://www.frontiersin.org/article/10.3389/fi mmu.2018.01891.

Lowes, Michelle A, Mayte Suarez-Farinas, and James G Krueger. 2014. "Immunology of Psoriasis." Annual Review of Immunology 32: 227-55. https://doi.org/10.1146/annurev-immunol032713-120225.

Mori, Hiroki, Kojo Arita, Takayuki Yamaguchi, Midori Hirai, and Yoichi Kurebayashi. 2016. "Effects of Topical Application of Betamethasone on Imiquimod-Induced Psoriasis-like Skin Inflammation in Mice." The Kobe Journal of Medical Sciences 62 (4): E79-88.

Ogawa, Eisaku, Yuki Sato, Akane Minagawa, and Ryuhei Okuyama. 2018. "Pathogenesis of Psoriasis and Development of Treatment." The Journal of Dermatology 45 (3): 264-72. https://doi.org/10.1111/1346-8138.14139.

Zokaei, Shaghayegh, Dariush D Farhud, Mohammad Keykhaei, Marjan Zarif Yeganeh, Hoda Rahimi, and Hamideh Moravvej. 2019. "Cultured Epidermal Melanocyte Transplantation in Vitiligo: A Review Article." Iranian Journal of Public Health 48 (3): 388-99. https://www.ncbi.nlm.nih.gov/pubmed/31223 565. 


\section{Egyptian Association for Cancer Research (EACR)}

http://eacr.tanta.edu.eg/

EACR is an NGO society that was declared by the Ministry of Social Solidarity (Egypt) No. 1938 in 19/11/2014 based on the initiative of Prof. Mohamed Labib Salem, the current Chairman of EACR. EACR aims primarily to assist researchers, in particular young researchers in the field of cancer research through workshops, seminars and conferences. Its first international annual conference entitled "Anti-Cancer Drug Discovery" was successfully organized in April 2019 (http://acdd.tanta.edu.eg). Additionally, EACR aims to raise the awareness of the society about the importance of scientific research in the field of cancer research in prediction, early diagnosis and treatment of cancer. EACR is also keen to outreach the scientific community with periodicals and news on cancer research including peer-reviewed scientific journals for the publication of cutting-edge research. The official scientific journal of EACR is "International Journal of Cancer and biomedical Research (IJCBR: https://jcbr.journals.ekb.eg) was successfully issued in 2017 and has been sponsored by the Egyptian Knowledge Bank (EKB: www.ekb.eg).

\section{EACR Chairman,}

Prof. Mohamed Labib Salem, PhD

Professor of Immunology

Faculty of Science, Tanta Universiy, Egypt 
International Journal of Cancer and Biomedical Research (IJCBR), a publication of the Egyptian Association for Cancer Research (EACR), is a peer-reviewed online journal published quarterly. The journal allows free access (Open Access) to its contents and permits authors to self-archive a final accepted version of the articles on any OAl-compliant institutional / subject-based repository.

\section{Aim And Scope}

Aim: The main aim of IJCBR is to attract the best research in animal and human biology in health and diseases from across the spectrum of the biomedical sciences at the molecular, cellular, organ, and whole animal levels especially those that are related to cancer research, including causes, prediction, diagnosis, prognosis and therapy.

Scope: It is essential reading for all researchers interested in biochemistry, cancer, microbiology, nutrition, physiology, genetics, immunology, epidemiology, medical economics, human biology, bioinformatics, biotechnology, nanotechnology, and disease modeling.

\section{Publication Ethics}

Researchers should conduct their research from research proposal to publication in line with the best practices and codes of conduct of relevant professional bodies and/or national and international regulatory bodies. IJCBR accepts manuscripts prepared in accordance with the "Uniform Requirements for Submission of Manuscripts for Biomedical Journals adopted by the International Committee of Medical Journal Editors (ICMJE) and the Committee on Publication Ethics (COPE). Details of ICMJE and COPE are available at http://www.icmje.org/ and http://publicationethics.org/

\section{Peer Review Process}

After the IJCBR editor receives a manuscript, the first step is to confirm that the manuscript meets the journal's rules for content and format, including similarity check (plagiarism) which should be less than $25 \%$. If the manuscript meets the journal's rules, the editor then assign it to the double-blind peer review process. The IJCBR editor send the manuscript to at least two experts in the field for RIGOROUS scientific evaluation. The experts called peer reviewers - will then prepare a report that assesses the manuscript and return it to the editor through the IJCBR portal. Upon the first submission, this reviewing process takes about 4 to 6 weeks. After reading the peer reviewer's report, the editor will decide one of the following four options:

1. Reject the manuscript.

2. Accept the manuscript

3. Ask the authors to revise and resubmit the manuscript after responding to the peer reviewers' feedback.

4. Ask for peer-review from additional reviewers.

If the authors resubmit the manuscript, the IJCBR editor will ask the same peer-reviewers to look over the manuscript again to confirm that their concerns have been addressed. This is called re-review process. This second revision (if applicable) takes about another 4 to 6 weeks. At this point, the abstract of the article appears in press. The online publication (the PDF format) of the final version of the manuscript takes from 2 to 4 weeks. As such, the total publication cycle takes from 2 to 4 months. This cycle can be reduced to 4 to 6 weeks (fast track publication) for the manuscripts with outstanding findings.

The peer-review process used by IJCBR includes comments on errors in the study's methods or analysis that raise questions about the findings, or sections that need clearer explanations. The peer-review process also includes the importance and novelty of the manuscript and its interest to the journal's audience. The IJCBR uses double-blind review, which means that both the reviewers and authors identities are concealed from the reviewers, and vice versa, throughout the review process. To facilitate this, authors need to submit a Title Page containing the Authors details and Blinded Manuscript with no author details as 2 separate files. 


\section{Publisher}

The International Journal of Cancer and Biomedical Research (IJCBR) is an International and interdisciplinary journal of preclinical and clinical studies in the area of cancer and biomedical research. It is a peer-reviewed journal in English, published quarterly (in March, June, September, and December) by the Egyptian Association for Cancer Research (EACR) in both print and online formats (4 issues making a volume). Special issues or supplements may also be produced from time to time upon agreement with the Editorial Board.

\section{Scope}

The main aim of IJCBR is to attract the best research in animal and human biology in health and diseases from across the spectrum of the biomedical sciences at the molecular, cellular, organ, and whole animal levels especially those that are related to cancer research, including causes, prediction, diagnosis, prognosis and therapy.

\section{Publication Fees}

The journal does charge for submission, processing or publication of manuscripts (2000 LE for Egyptians or $\$ 300$ for non-Egyptians; EACR members receive 15\% discount on publication). Of them Peer-review fees (300 LE) should be paid on submission (non-refundable). For the fast track production of the accepted manuscript, another $500 \mathrm{LE}$ is paid.

General specifications for different types of article

- Submitted manuscripts should not have been published previously, except in a limited form (e.g. short communication to a symposium or as part of MSc or PhD theses) and should not be under consideration for publication by other journals.

- All co-authors should agree with the content of the manuscript. Authors must have obtained permission to use any copyrighted material in the manuscript before submission.

\section{IJCBR publishes different types of articles}

- Original Article (6000 words with $\mathbf{4}$ tables and $\mathbf{4}$ figures, maximum $\mathbf{8}$ display items): Articles with novel findings are the target of IJCBR. Articles presenting a detailed description of a new technique, comparison of existing methods, meta-analyses with comprehensive and in-depth discussion are considered. Papers in a numbered series are not accepted unless all are submitted at the same time.

- Short communications or case study (3000 words with 4 display items): Short communications present exceptionally exciting, novel or timely contents are considered. They will be peer-reviewed in the same way as research papers. The references are restricted to 15 .

- Reviews or systematic review (9000 words with $\mathbf{1 0}$ display items): They are invited by the Editorial Board or unsolicited. Review articles have to be contemporary and comprehensive and add information to the knowledge. Sharp critical analyses of novel data or concepts are encouraged. When relevant, a statistical analysis of data and a meta-analysis approach are recommended.

- Opinion papers, letter to the editor or comment to the editor (1500 words with $\mathbf{2}$ display items): They are submitted by invitation of the Editorial Board. They are short papers, which aim to inform scientists, industry, and the public and policymakers about cutting-edge issues in research or the impact of research. They reflect the opinion of their authors who bear full responsibility of the published paper. The references are restricted to 10 .

- Conference/Symposium papers: The journal will consider for publication the results of original work and critical reviews that are presented at conferences/symposia. Symposium organizers who wish to publish bundles of papers from a symposium/conference in IJCBR should first contact the Editor-inChief of the IJCBR (EACR@unv.tanta.edu.eg) for agreement. Supplementary material can be proposed and will be made available online. The responsibility for the preparation of a paper in a form suitable for publication lies with the author.

- Thesis: IJCBR can publish the summary and abstract of Master and PhD theses in a special issue. 
English: Good quality of written English is required. Spelling may be in British or American English but must be consistent throughout the paper. Care should be exercised in the use of biological terminology that is ill-defined or of local familiarity only. We recommend that authors have their manuscripts checked by an English language native speaker before submission.

Manuscript layout: Manuscripts should be prepared using a standard word processing program and presented in a clear readable format with easily identified sections and headings. The manuscript layout is based on the following directions.

- The main text contains Title, Abstract, Keywords, Introduction, Material and Methods, Results, Discussion, References, Tables, figures.

- The title needs to be concise and informative. Use bold, with an initial capital for the first word only and for words that ordinarily take capitals

- Short (running) title (max 80 characters including spacing).

- The article text should be typed with double-line spacing with wide margins $(2.5 \mathrm{~cm})$.

- The lines must be continuously numbered; the pages must also be numbered.

- Font Calibri 12 should be used for the text, and 12 for the tables, figure legends and references.

- The sections should typically be assembled in the following order:

- Title page contains title, authors' names, full affiliations, acknowledgements and the corresponding author's contacts and Short title.

Abstract (max 250 words, single paragraph): The abstract should be complete and understandable without citation, references, table or figure. Use structured abstract: Background, Aim, Materials \& Methods, Results and Conclusion. The context and the rationale of the study are presented succinctly to support the objectives. The experimental methods and main results are summarized but should not be overburdened by numerical values or probability values. The abstract ends with a short and clear conclusion.

Keywords: Up to five short and specific keywords should complement the title with respect to indicating the subject of the paper in alphabetic order.

Introduction: The introduction briefly outlines the context of the work, presents the current issues that the authors are addressing and the rationale to support the objectives, and clearly defines the objectives.

Material and methods: Material and methods should be described in sufficient details so that others can repeat the experiment. Reference to previously published work may be used to give methodological details, provided that said publications are readily accessible and in English. The code of ethics should be followed for all experiments use animals or human samples.

Statistical analysis of results: The statistical design and the models of statistical analysis must be described, as well as each of the statistical methods used. Sufficient statistical details must be given to allow replication of the statistical analysis. The experimental unit should be defined (e.g. individual or group of animals).

Results: Data are presented as tables and figures. Brief description of the results for each table and figure should be presented. Unpublished data can be mentioned when necessary.

Discussion: Should be separate from the Results section and should focus only on intra- and inter-data discussion (the data in the results section) as well as with the relative data in the literature. Don't repeat information already presented in the Introduction section. Start the first paragraph in the Discussion with a paragraph stating the rationale behind the study, the objectives and the main findings. End Discussion with a short conclusion.

Acknowledgements: In this section, the authors may acknowledge (briefly) their support staff.

Conflict of interest: All papers with a potential conflict of interest must include a description/explanation in a separate heading.

Funding details: The authors should state the source of findings of the study (with research funder and/or grant number). If no fund, the authors should state that the study is self-funded. 


\section{References}

Citation of references: In the text, references should be cited by the author(s) surname(s) and the year of publication (e.g. Salem, 2020). References with two authors should be cited with both surnames (e.g. Salem and Meshrif, 2021). References with three or more authors should be cited with the first author followed by et al. (in italics; e.g. Salem et al., 2021). Names of organizations used as authors (e.g. Food and Drug Administration) should be written out in full in the list of references and on the first mention in the text. Subsequent mentions may be abbreviated (e.g. FDA).

- List of references. Literature cited should be listed in alphabetical order by authors' names. It is the author's responsibility to ensure that all references are correct. All authors should be written and so the full journal name.

- References from journal articles are formatted in APA as this example: Al-Amoudi WM (2018). Toxic effects of Lambda-cyhalothrin on the rat thyroid. Involvement of oxidative stress and ameliorative effect of ginger extract. Toxicology Reports, 5: 728-736.

- References from books or official reports are formatted as this example. Kebreab E, Dijkstra ANM, Bannink A, Gerrits WJJ, \& France J (2006). Nutrient digestion and utilization in farm animals. CABI Publishing. Wallingford, UK.

- References from chapters or parts of books are formatted as this example. Nozière $P, \&$ Hoch $T$ (2006). Modelling fluxes of volatile fatty acids from rumen to portal blood. In: Nutrient digestion and utilization in farm animals (Kebreab E, Dijkstra ANM, Bannink A, Gerrits WJJ \& France J, eds.), pp. 40-47. CABI Publishing. Wallingford, UK.

Tables:

The data should be presented in tables or in graphs, not both.

- Each table should be placed on a separate page at the end of the main text.

- Tables are numbered consecutively using Arabic numbering. They are referred to as Table 1 , Table 2, etc., with capital ' $T$ ', no italics

- Each table has its explanatory caption. The caption is sufficient to permit the table to be understood without reference to the text.

- Abbreviations used in tables/figures have to be defined either as footnotes or in the caption.

Figures

- Package the figures in a single PowerPoint file. Each figure in a separate slide.

- Figure size should be readable in a width of approximately 8-175 $\mathrm{mm}$ (i.e. the maximum size of printing over two columns).

- Ensure that the font size is large enough to be readable at the final print size, use Calibri font to ensure that they are consistent throughout the figures.

- The figures should preferably be provided as TIFF or EPS files.

- The resolutions of figures must be at least $300 \mathrm{dpi}$.

- Preparation of images for a manuscript: For guidance, we refer to the Journal of Cell Biology's instructions to authors (http://jcb.rupress.org/site/misc/ifora.xhtml\#image_aquisition).

- If a cropped image is included in the main text of a paper (e.g. a few lanes of a gel), display the full original image, including the appropriate controls, the molecular size ladder and/or the scale as relevant, as a single figure in a Supplementary Material file to facilitate peer-review and for subsequent online publication.

- Supplementary material is submitted along with the main manuscript in a separate file and identified at uploading as "Supplementary File - for Online Publication Only" The title of the article is included at the top of the supplementary material.

Corresponding author's guidelines: Upon acceptance the corresponding author is required to send his/her recent formal photo to be attached to the front page of the article. 


\title{
International Journal of Cancer \& Biomedical Research
}

(IJCBR) Online ISSN 2682-2628

\author{
Editor-in-Chief \\ Mohamed Labib Salem, PhD \\ Tanta University, Egypt
}

\begin{tabular}{l} 
EACR Board \\
\hline Nehal Elmashad, MD \\
Tanta University, Egypt \\
Nabil Mohy Eldin, PhD \\
Kafrelsheikh University, Egypt \\
Doaa Al-Ghareeb, PhD \\
Alexandria University, Egypt \\
Abdel-Aziz Zidan, PhD \\
Damanhour University, Egypt
\end{tabular}

\begin{tabular}{l} 
Managing Editor \\
\hline Wesam Meshrif, PhD \\
Tanta University, Egypt \\
Sohaila Galal, PhD \\
Tanta University, Egypt \\
Production and Contact \\
\hline Hamdi Kandil \\
Tanta University, Egypt \\
Email: ljcbr100@gmail.com
\end{tabular}

\section{Advisory Board}

Alberto Montero, MD

Taussig Cancer Center, Cleveland,

USA

Yi Zhang, MD

Zhengzhou University, China

Mark Robunstein, Ph D

Medical University of South

Carolina, USA

Mohsen Farid, Ph D

Derby University, USA

Natarajan Muthusamy, Ph D

Ohio State University, USA

Hideki Kasuya, MD

Nagoya University, Japan

Sherif El-Khamisy, Ph D

Sheffield University, UK

Mohamed Ghanem, Ph D

Kafr Elshikh University, Egypt

Sayed Bakry, Ph D

Alazhar University, Egypt

Sameh Ali, Ph D

Nationa Liver Institute, Egypt

Gamal Badr, Ph D

Assuit University, Egypt

Nadia Hamdy, Pharm D

Ain Shams University, Egypt

\section{Editorial Board}

\section{Clinical studies}

Hesham Tawfik, MD

Tanta University, Egypt

Mohamed Attia, MD

Tanta University, Egypt

Mohamed Elshanshory, MD

Tanta University, Egypt

Essam Elshiekh, MD

Tanta Cancer Center, Egypt

Rasha Eraky, MD

Tanta University, Egypt

Shaima Abou-Kjatwa, MD

Tanta University, Egypt

Marcela Diaz, MD

Cleveland Clinic Foundation, USA

Mohamed Abou-El-Enein, MD

Charité Universitätsmedizin Berlin,

Germany
Alaa Eldin Almostafa, MD

McGill University, Canada

Olfat Gadallah, MD

Tanta University, Egypt

Nagla Sarhan, MD

Tanta University, Egypt

Naglaa Fathy, Pharm D

Zagazik University, Egypt

Mohamed Salama, MD

Mansoura University, Egypt

Mona Marie, MD

Alexandria University, Egypt

Preclinical studies

Mostafa El-Sheekh

Tanta University, Egypt

El-Refai Kenawy, Ph D

Tanta University, Egypt

Mohamed Noureldin, Ph D

Banaha University, Egypt

Yousry Albolkiny, Ph D

Tanta University, Egypt

Elsayed Salim, Ph D

Tanta University, Egypt

Shengdian Wang, Ph D

Chinese Academy of Sciences,

China

Sabry El Naggar, Ph D

Tnata Univesity, Egypr

Faris Alenzi, Ph D

Prince Sattam bin Abdulaziz

University, KSA

Ibrahim El-Sayed, Ph D

Menoufia University, Egypt

Tarek Aboul-Fadl, Ph D

Assiut University, Egypt

Rabab Khairat, Ph D

National Research Center,

Giza, Egypt

Wael Lotfy, Ph D

Alexandria University, Egypt

Ashraf Tabll, Ph D

National Research Center, Egypt

Nahla Shoukry, Ph D

Suez University, Egypt
Medhat Eldenary, Ph D

Tanta University, Egypt

Azza Hasan, Ph D

Menufia University, Egypt

Nanees Gamal Eldin, Ph D

Tanta University, Egypt

Mohamed Mansour, UK

Sabbah Hammoury, Ph D

Alexandria Ayadi Almostaqba

Oncology Hospital, Egypt

Nehal Aboulfotoh, Ph D

Zewail City for Science and

Technology, Cairo, Egypt

Amir Elkhami, Ph D

Galaxo, San Francisco, USA

Ahmed Alzohairy, Ph D

Zagazi University, Egypt

Wgady Khalil, Ph D

National Research Center, Egypt

Amr Amin, Ph D

United Arab Emirates

University, UAE

AbdelRahman Zekri, Ph D

National Cancer Institute, Egypt

Hussein Khamis, Ph D

Alexandria University, Egypt

Magdy Mahfouz, Ph D

Kafr Elsheikh University, Egypt

Ehab Elbedewey, Ph D

Tanta University, Egypt

Abeer Badr, Ph D

Cairo University, Egypt

Mamdooh Ghoneum, Ph D

Charles Drew University of

Medicine \& Science, USA

Haiam Abou Elela, Ph D

National Institute of Oceanography and Fisherie, Egypt

Maha EL-Demellawi, Ph D City for Scientific Research \&

Technology Applications, Egypt

Desouky Abd-El-Haleem, Ph D

City for Scientific Research \&

Technology Applications, Egypt 